\title{
Histologically confirmed upper gastrointestinal Crohn's disease: is it rare or are we just not searching hard enough?
}

\author{
Omar Ibrahim Saadah ${ }^{1,2}$, Kholoud Bakur Fallatah ${ }^{3}$, Cedric Baumann ${ }^{4}$, Abdulrahman Ahmed Elbaradie ${ }^{3}$, \\ Fatimah Talat Howladar ${ }^{3}$, Motaz Tariq Daiwali ${ }^{3}$, Omar Hamad Alshuaibi ${ }^{3}$, Majid Abdulaziz Alsahafi ${ }^{2,3}$, \\ Rana Yaqoob Bokhary ${ }^{2,5}$, Yousef Abdulfattah Qari ${ }^{2,3}$, Laurent Peyrin-Biroulet ${ }^{4}$, Mahmoud Hisham Mosli ${ }^{2,3}$ \\ ${ }^{1}$ Department of Pediatrics, King Abdulaziz University Faculty of Medicine, Jeddah; ${ }^{2}$ Inflammatory Bowel Disease Research Group, King \\ Abdulaziz University, Jeddah; ${ }^{3}$ Department of Medicine, King Abdulaziz University Faculty of Medicine, Jeddah, Saudi Arabia; ${ }^{4}$ Clinical \\ Research Support Facility, Methodological and Statistical Unit, University Hospital of Nancy, Nancy, France; ${ }^{5}$ Department of Pathology, King \\ Abdulaziz University Faculty of Medicine, Jeddah, Saudi Arabia
}

Background/Aims: Crohn's disease (CD) may involve the upper parts of the gastrointestinal (GI) tract including the esophagus, stomach, and duodenum. Clinical features of upper GI CD (UGICD) are not well characterized in the Gulf region. We therefore aimed to assess the prevalence and clinical characteristics of patients diagnosed with UGICD. Methods: We performed a retrospective analysis of all patients diagnosed with CD who underwent upper GI endoscopy between 2012 and 2017 at King Abdulaziz University Hospital, irrespective of age. Patients who had endoscopy of the upper GI tract at baseline and had histologically confirmed UGICD were included. Data on patients' demographics, clinical characteristics, extraintestinal manifestations and complications were reviewed. Results: We identified $78 \mathrm{CD}$ patients who underwent upper GI endoscopy from our medical records. The mean age was $17.2 \pm 8.7$ years and $55.1 \%$ were males. Of the total, 19 out of 78 patients $(24.4 \%)$ had histologically confirmed UGICD ( 3 esophageal, 16 gastric, and 9 duodenal), of which $52.6 \%$ were symptomatic. Disease distribution was ileal in $57.8 \%$, colonic in $21.1 \%$ and ileo-colonic in $21.1 \%$. A non-stricturing and non-penetrating phenotype was reported in $89.4 \%$, stricturing in $5.3 \%$, and penetrating in $5.3 \%$. Perianal disease was found in $10.5 \%$. UGICD was complicated by stricture formation in 2 patients (esophageal and gastric). Conclusions: The prevalence of UGICD is considered high among CD Saudi patients who undergo upper GI endoscopy at baseline, and is asymptomatic in $47.4 \%$ of patients. This reported prevalence is not dissimilar from reports originating from Western countries. (Intest Res 2020;18:210-218)

Key Words: Crohn disease; Inflammatory bowel disease; Esophagitis; Gastro-duodenal; Saudi Arabia

\section{INTRODUCTION}

Inflammatory bowel disease (IBD) refers to a group of chronic inflammatory disorders that affect the GI tract. ${ }^{1}$ IBD is divided into 2 main clinical types: CD and UC. CD can occur in any part of the GI tract, commonly in the ileo-colonic region, but it can also affect the upper GI tract.

Received August 5, 2019. Revised November 11, 2019.

Accepted November 30, 2019.

Correspondence to Omar Ibrahim Saadah, Pediatric Gastroenterology Unit,

Department of Pediatrics, King Abdulaziz University Faculty of Medicine, PO

Box. 80205 Jeddah 21589, Saudi Arabia. Tel: +996-126401000 (ext. 20202),

Fax:+966-126408353, E-mail: osaadah@kau.edu.sa
According to the European Crohn's and Colitis Organisation, no standard diagnostic reference exist for the diagnosis of CD; diagnosis is based on a combination of clinical, endoscopic, and histological features. ${ }^{2}$ Upper GI CD (UGICD) is uncommon in adults, occurring in 0.3 to $5 \%$ of adult patients with $\mathrm{CD}^{3}$ Conversely, it has been found that $28 \%$ of adolescents and $43 \%$ of pediatric patients with CD have UGICD., ${ }^{4,5}$ This variation between adult patients and adolescents and pediatric patients could be explained by the variation in the practice of diagnosing adult and pediatric patients with CD. Pediatric gastroenterologists tend to perform upper endoscopy more often than adult gastroenterologists during the evalua- 
tion of patients for possible CD diagnosis, in accordance with the recommendations of the European Society for Pediatric Gastroenterology Hepatology and Nutrition (ESPGHAN) revised Porto criteria. ${ }^{6}$

The incidence of foregut CD has been reported in $40 \%$ of adult patients who had prospective upper endoscopy after confirming the diagnosis of $\mathrm{CD}$, and only $32 \%$ of the patients experience symptoms. ${ }^{7}$ Endoscopic abnormalities of the upper GI tract including mucosal erosions, aphthous ulceration, and mucosal thickening have been reported in $56 \%$ of adults with $\mathrm{CD}^{8}$

A diagnosis of $\mathrm{CD}$ of the upper GI tract is carried out by a combination of clinical, endoscopic, and histological features. ${ }^{9,10}$ The histopathological examination of the biopsies acquired from the lower esophagus, stomach, and the duodenum of $\mathrm{CD}$ patients with an endoscopically normal upper GI tract may reveal pathognomonic $\mathrm{CD}$ lesions ${ }^{11}$ and since granulomas can be found in variety of conditions involving the GI tract, exclusion of such conditions is required before accepting the presence of non-caseating granulomas as the histological proof of $\mathrm{CD}{ }^{9}$

The confirmation of the presence of UGICD in patients with CD is of prognostic value. Patients with UGICD manifestations are at higher risk of more aggressive stricturing and a more penetrating form of the disease, meaning more recurrences, frequent hospitalization, and more surgical interventions. ${ }^{12}$

Studies addressing the subject of UGICD in Saudi patients are lacking, therefore this study aimed to determine the prevalence and clinical characteristics of UGICD in a cohort of Saudi patients, and to identify significant clinical predictors of UGICD.

\section{METHODS}

The King Abdulaziz University Hospital (KAUH) Inflammatory Bowel Disease Information System (IBDIS) registry was utilized to conduct a retrospective analysis. The IBDIS registry is a web-based database that has been used to register IBD patients following up at KAUH since January 2018. IBDIS contains demographic, clinical, endoscopic, laboratory, radiological, and endoscopic data. The hospital electrical medical records were also accessed for supplementary data. We first went through our IBD database and isolated patients with confirmed CD rather than UC, then we identified those from this cohort who had upper GI endoscopy at baseline, following this we started to collect the relevant data. All patients diagnosed with CD prior to 2017 that underwent upper GI endoscopy with biopsies were identified in IBDIS and included in this analysis with no age restrictions. Diagnosis of CD was based on standard clinical, endoscopic, and histological criteria 2.

\section{Inclusion Criteria}

All patients with a confirmed diagnosis of $\mathrm{CD}$ who had simultaneous upper GI endoscopy performed at the time of diagnosis were included.

\section{Exclusion Criteria}

Patients with a known diagnosis of gastroesophageal reflux disease/esophagitis and patients with known peptic ulcer disease, active Helicobacter pylori infection or patients on NSAIDs were excluded. Patients with confirmed tuberculosis or those who received corticosteroid treatment prior to endoscopy were also excluded.

\section{Endoscopic Evaluations}

Upper GI endoscopy procedures without chromoendoscopy or image image-enhanced endoscopy were performed by experienced gastroenterologists under general anesthesia for children or conscious sedation for adolescents and adults simultaneously with ileocolonoscopy at the time of diagnosis for all patients. Multiple biopsies were regularly taken from the esophagus, gastric body, gastric antrum and second part of the duodenum. Additional targeted biopsies were performed if abnormal lesions were found. Rapid urease test (CLOtest) was routinely performed on biopsy specimens taken from the gastric antrum as an initial screening test for $H$. pylori prior to histopathological identification.

\section{Histologic Criteria for UGICD}

The histological diagnosis was determined according to the European consensus on histopathology of IBD, ${ }^{13}$ and the British Society of Gastroenterology guidelines in reporting IBD biopsies. ${ }^{14}$ The microscopic findings in the esophagi that were considered diagnostic for $\mathrm{CD}$ included: increased intraepithelial lymphocytes, focal infiltration of the lamina propria by mononuclear inflammatory cells, and histiocytes with or without formation of non-caseating granulomas. The findings of the gastro-duodenal biopsies included: granulomatous gastritis and focally enhanced (active) H. pylori negative gastritis, or a large number of macrophage aggregates, seen throughout the lamina propria. ${ }^{5,15}$ All histopathological specimens were reviewed and reported by an experienced and certified GI pathologist with special interest in IBD. We did not rely on central pathological diagnosis for inclusion into this study. 


\section{Outcomes}

The prevalence of histologically confirmed CD in the esophagus, stomach, or duodenum was considered the primary outcome of this study. Secondary outcomes included identifying clinico-demographic predictors of upper GI tract CD.

\section{Statistical Analysis}

Descriptive statistics were applied to the raw data: for quantitative variables, means, $\mathrm{SD}$, and minimum and maximum values were obtained; for qualitative variables, we used frequency measurement. The prevalence of upper GI tract CD was calculated. Chi-square and Fisher exact tests were used to delineate the relationship between patients' demographic and clinical features and upper GI tract CD, based on a $P$-value of $<0.05$. Analyses were made using SAS version 9.4 (SAS Institute, Cary, NC, USA).

\section{Ethical Oversight}

Ethical considerations in accordance with the Declaration of Helsinki were followed throughout this study. This study was approved by the Research Committee/Biomedical Ethics Unit at King Abdulaziz University (Reference No. 398-17). All patients signed an informed consent prior to the endoscopy procedures that were performed for diagnostic purposes.

\section{RESULTS}

\section{Baseline Characteristics}

A total of 135 patients with CD were identified in IBDIS, but only 78 patients ( $57.8 \%$ ) fulfilled the study criteria and underwent upper GI endoscopy between 2012 and 2017. Forty-three patients $(55.1 \%)$ were males with a male to female ratio of 1.2:1 and the overall mean age was $17.2 \pm 8.7$ years (with a range of 3-52 years). Extraintestinal manifestations of CD were reported in $17.9 \%$ of all patients $(n=14)$ and in $14 \%$ of patients $(\mathrm{n}=8)$ diagnosed aged 18 or younger. Overall, $35.9 \%$ $(\mathrm{n}=28), 33.3 \%(\mathrm{n}=26)$, and $30.8 \%(\mathrm{n}=24)$ had ileal, colonic, and ileo-colonic disease, respectively. The most common pattern of disease behavior was non-stricturing, non-penetrating disease (B1; 87.2\%), followed by stricturing (B2; 9.0\%), then penetrating (B3; 3.8\%) disease. Perianal involvement (P) occurred in $10 \%$ of cases.

The most frequently reported symptoms at baseline were diarrhea (72.0\%), abdominal pain (65.4\%), weight loss (56.4\%), and fatigue (50.0\%). Other less common symptoms included vomiting (26.9\%), aphthous stomatitis (10.3\%), joints pain
Table 1. Baseline Characteristics of the Study Cohort

\begin{tabular}{|c|c|}
\hline Characteristic & Value $(n=78)$ \\
\hline \multicolumn{2}{|l|}{ Demographics } \\
\hline Age (yr) & $17.2 \pm 8.7$ \\
\hline Female sex & $35(44.9)$ \\
\hline Saudi nationality & 64 (82.0) \\
\hline \multicolumn{2}{|l|}{ Comorbidities } \\
\hline Diabetes mellitus & $1(1.3)$ \\
\hline Hypertension & $1(1.3)$ \\
\hline \multicolumn{2}{|l|}{ Family history } \\
\hline Family history of IBD & $5(6.4)$ \\
\hline History of parental consanguinity & $18(23.0)$ \\
\hline \multicolumn{2}{|l|}{ Presenting symptoms } \\
\hline Diarrhea & $56(72.0)$ \\
\hline Abdominal pain & $51(65.4)$ \\
\hline Weight loss & $44(56.4)$ \\
\hline Fatigue & $39(50.0)$ \\
\hline Vomiting & $21(26.9)$ \\
\hline Dysphagia & $2(2.6)$ \\
\hline \multicolumn{2}{|l|}{ Montreal classification } \\
\hline \multicolumn{2}{|l|}{ Age group } \\
\hline$A 1(<17 \mathrm{yr})$ & $44(56.4)$ \\
\hline A2 (17-40 yr) & $31(39.7)$ \\
\hline A3 $(>40 \mathrm{yr})$ & $3(3.8)$ \\
\hline \multicolumn{2}{|l|}{ Location } \\
\hline L1 (Terminal ileal) & $28(35.9)$ \\
\hline L2 (Colonic) & 26 (33.3) \\
\hline L3 (Ileo-colonic) & $24(30.8)$ \\
\hline \multicolumn{2}{|l|}{ Behavior } \\
\hline B1 (Non-stricturing, non-penetrating) & $68(87.2)$ \\
\hline B2 (Stricturing) & $7(9.0)$ \\
\hline B3 (Penetrating) & $3(3.8)$ \\
\hline \multicolumn{2}{|l|}{ Extraintestinal manifestations } \\
\hline Aphthous stomatitis & $8(10.3)$ \\
\hline Perianal disease & $8(10.3)$ \\
\hline Eye inflammation & $3(3.8)$ \\
\hline Complications of CD & $24(30.8)$ \\
\hline \multicolumn{2}{|l|}{ Laboratory investigations } \\
\hline Leukocyte count $\left(\times 10^{3} / \mu \mathrm{L}\right)$ & $9.0 \pm 3.1$ \\
\hline Hemoglobin (g/dL) & $10.1 \pm 3.1$ \\
\hline Platelets $\left(\times 10^{3} / \mu \mathrm{L}\right)$ & $507.6 \pm 164.3$ \\
\hline Albumin $(g / L)$ & $26.0 \pm 7.7$ \\
\hline $\mathrm{CRP}(\mathrm{mg} / \mathrm{L})$ & $49.5 \pm 42.0$ \\
\hline
\end{tabular}

Values are presented as mean \pm SD or number $(\%)$. 
(12.8\%), and eye inflammation (3.8\%). Only 2 patients (2.6\%) reported having dysphagia. Thirty-one percent of the sample developed complications of CD: malnutrition (19\%), strictures

Table 2. Distribution of UGICD Histopathological Abnormalities According to Age

\begin{tabular}{lccccc}
\hline $\begin{array}{l}\text { Location } \\
\text { UGICD }\end{array}$ & \multicolumn{2}{c}{ Age $(\mathrm{yr})$} & & Total \\
\cline { 2 - 3 }$(\mathrm{n}=14)$ & $\begin{array}{c}>18 \\
(\mathrm{n}=5)\end{array}$ & $\begin{array}{c}\text { \% of the } \\
(\mathrm{n}=19)\end{array}$ & $\begin{array}{c}\text { total cohort } \\
(\mathrm{n}=78)\end{array}$ & $P$-value ${ }^{\mathrm{a}}$ \\
\hline Esophageal & 3 & 0 & 3 & 3.8 & 1.0 \\
Gastric & 12 & 4 & 16 & 20.5 & \\
Duodenal & 7 & 2 & 9 & 11.5 & \\
Non UGICD & 43 & 16 & & & \\
\hline
\end{tabular}

${ }^{a}$ Fisher exact test.

UGICD, upper GI CD.
(11.5\%), and fistula (10.3\%) were most common. Others encountered complications including bowel resection (9\%), abscesses (5.1\%), and bowel perforation (3.8\%). Only $6.4 \%$ of pa-

Table 3. Upper GI Endoscopic Findings of Patients with UGICD $(n=19)$

\begin{tabular}{lccc}
\hline Endoscopic finding & Esophagus & Stomach & Duodenum \\
\hline Normal & $16(84.2)$ & $3(15.8)$ & $12(63.2)$ \\
Erythema & 0 & $5(26.3)$ & $5(26.3)$ \\
Erosions & 0 & $8(42.1)$ & 0 \\
Aphthous ulcerations & $2(10.5)$ & $2(10.5)$ & $2(10.5)$ \\
Stricture & $1(5.3)$ & $1(5.3)$ & 0 \\
\hline
\end{tabular}

Values are presented as number (\%).

UGICD, upper GI CD.
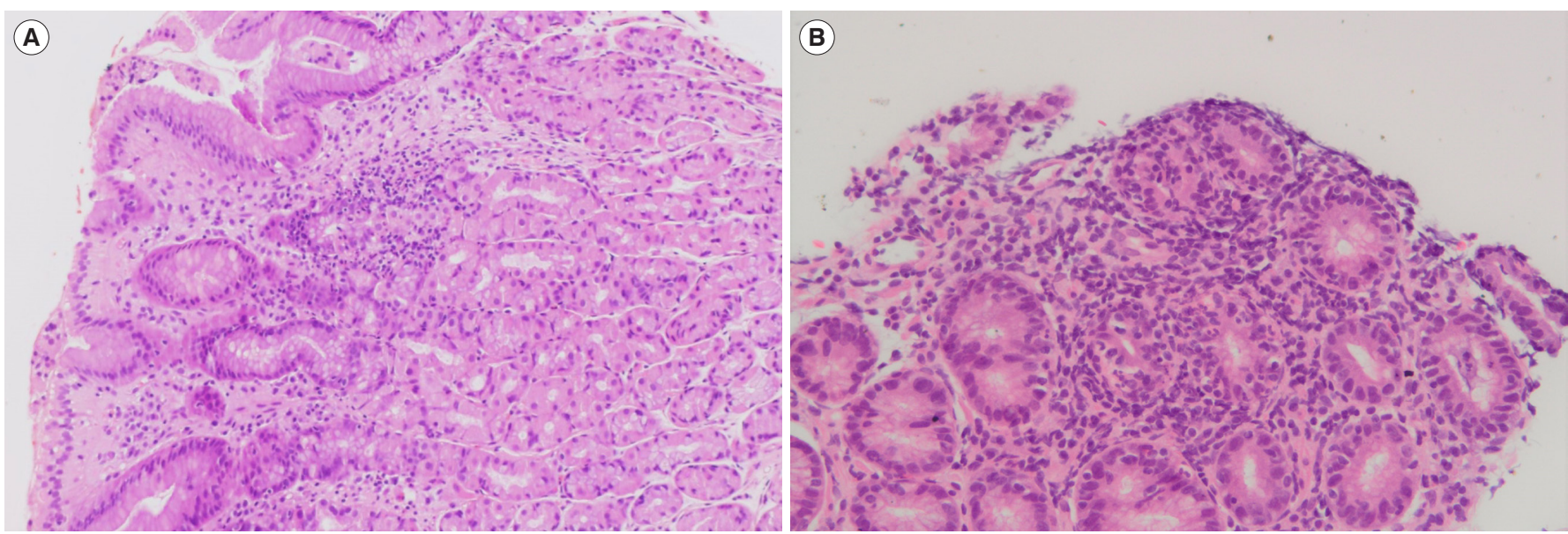

Fig. 1. Focally enhanced gastritis. (A) Low power view of gastric body-type mucosa with patchy chronic gastritis (H\&E, $\times 100)$. (B) High detail showing dense collection of chronic inflammatory cells around some antral glands with neutrophils infiltrating the glandular epithelium $\left(H \& E_{1} \times 200\right)$.
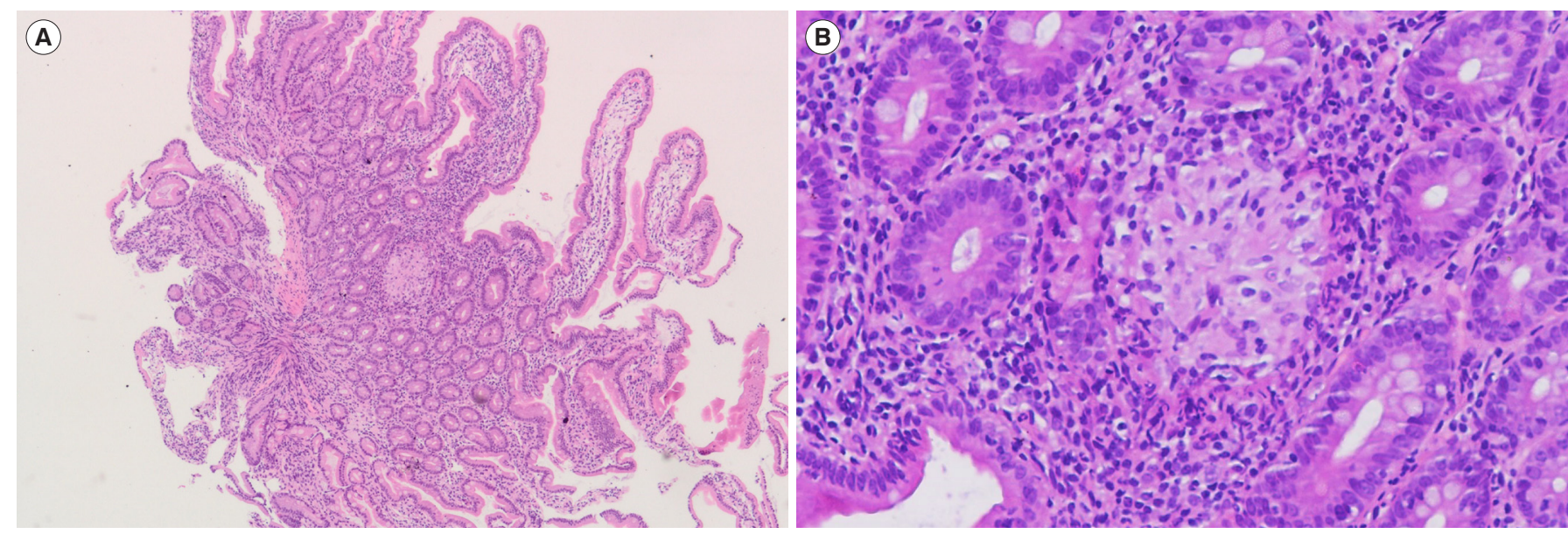

Fig. 2. Non-caseating granuloma in duodenal biopsy. (A) Low power view $\left(H \& E_{1} \times 40\right)$ and $(B)$ high power view $\left(H \& E_{1} \times 200\right)$. 
tients reported a family history of CD and $23 \%$ had a history of parental consanguinity (parents are first-degree cousins) that may suggest genetics association with disease occurrence. All baseline characteristics are summarized in Table 1. We did not encounter any patient in our cohort with symptoms of chest pain or sore throat at the time of performing diagnostic endoscopy.

\section{Study Outcomes}

Nineteen patients (24.4\%) had histologically confirmed UGICD. Three (3.8\%), 16 (20.5\%), and 9 patients (11.5\%) were located in the esophagus, stomach, and duodenum, respectively (Table 2). The upper GI endoscopic examination of all patients with UGICD showed normal looking mucosa in the esophagus, stomach, and duodenum in $84.2 \%, 15.8 \%$, and $63.2 \%$, respectively, in addition to various other abnormalities such as erythema, erosions, aphthous ulcerations, and stricture formation that are summarized in Table 3. Confirmed histopathological abnormalities included chronic active esophagitis (15.8\%), chronic active gastritis (52.6\%), focal enhanced gastritis (31.6\%), chronic active duodenitis (36.8\%), focal chronic active duodenitis (10.5\%), villous atrophy (5.3\%), and duodenal non-caseating granuloma (5.3\%) (Table 4). The histopathological features of focal enhanced gastritis and duodenal non-caseating granuloma are depicted in Figs 1 and 2, respectively. Ten of the 19 (52.6\%) patients with UGICD had upper GI symptoms. Nausea and vomiting were reported by 9 patients (47.4\%), epigastric pain by 6 (31.6\%), dysphagia by $2(10.5 \%)$, and aphthous stomatitis by 2 (10.5\%). There was no significant differences demonstrated between patients with and patients without upper GI symptoms with regards to baseline characteris-

Table 4. Histopathological Findings of Patients with UGICD $(n=19)$

\begin{tabular}{ll}
\hline Histopathological finding & No. (\%) \\
\hline Esophageal biopsy & $3(15.8)$ \\
Chronic active esophagitis & \\
Gastric biopsy & $10(52.6)$ \\
Chronic active gastritis & $6(31.6)$ \\
Focal enhanced gastritis & \\
Duodenal biopsy & $7(36.8)$ \\
Chronic active duodenitis & $2(10.5)$ \\
Focal chronic active duodenitis & $1(5.3)$ \\
Villous atrophy & $1(5.3)$ \\
Granuloma
\end{tabular}

UGICD, upper GI CD.
Table 5. Comparison between Patients with and without Upper GI Symptoms

\begin{tabular}{|c|c|c|c|}
\hline Characteristic & $\begin{array}{c}\text { Asympto- } \\
\text { matic } \\
(n=9)\end{array}$ & $\begin{array}{c}\text { Sympto- } \\
\text { matic } \\
(n=10)\end{array}$ & $P$-value ${ }^{a}$ \\
\hline \multicolumn{4}{|l|}{ Baseline characteristics } \\
\hline Sex & & & 0.65 \\
\hline Male & $6(66.7)$ & $5(50.0)$ & \\
\hline Female & $3(33.3)$ & $5(50.0)$ & \\
\hline Nationality & & & 0.58 \\
\hline Saudi & $8(88.9)$ & $7(70.0)$ & \\
\hline Non Saudi & $1(11.1)$ & $3(30.0)$ & \\
\hline Parental consanguinity & & & 0.58 \\
\hline Yes & 8 (88.9) & $7(70.0)$ & \\
\hline No & $1(11.1)$ & $3(30.0)$ & \\
\hline \multicolumn{4}{|l|}{ Montreal classification } \\
\hline Age group & & & 0.23 \\
\hline $\mathrm{A} 1$ (<17 yr) & $6(66.7)$ & $3(30.0)$ & \\
\hline A2 (17-40 yr) & $3(33.3)$ & $6(60.0)$ & \\
\hline $\mathrm{A} 3(>40 \mathrm{yr})$ & 0 & $1(10.0)$ & \\
\hline Location & & & 0.25 \\
\hline L1 (Terminal ileal) & 7 (77.8) & $4(40.0)$ & \\
\hline L2 (Colonic) & $1(11.1)$ & $3(30.0)$ & \\
\hline L3 (Ileo-colonic) & $1(11.1)$ & $3(30.0)$ & \\
\hline Behavior & & & 0.37 \\
\hline $\begin{array}{l}\text { B1 (Non-stricturing \& non- } \\
\text { penetrating) }\end{array}$ & $8(88.9)$ & $9(90.0)$ & \\
\hline B2 (Stricturing) & 0 & $1(10.0)$ & \\
\hline B3 (Penetrating) & $1(11.1)$ & 0 & \\
\hline \multicolumn{4}{|l|}{ Endoscopy findings } \\
\hline Esophageal & & & 0.62 \\
\hline Normal & $8(88.9)$ & $8(80.0)$ & \\
\hline Aphthous ulcers & $1(11.1)$ & $1(10.0)$ & \\
\hline Stricture & 0 & $1(10.0)$ & \\
\hline Gastric & & & 0.32 \\
\hline Normal & $3(33.3)$ & 0 & \\
\hline Erythema & $2(22.2)$ & $3(30.0)$ & \\
\hline Erosions & $3(33.3)$ & $5(50.0)$ & \\
\hline Aphthous ulcers & $1(11.1)$ & $1(10.0)$ & \\
\hline Stricture & 0 & $1(10.0)$ & \\
\hline Duodenal & & & 0.34 \\
\hline Normal & $6(66.7)$ & $6(60.0)$ & \\
\hline Erythema & $3(33.3)$ & $2(20.0)$ & \\
\hline Aphthous ulcers & 0 & $2(20.0)$ & \\
\hline
\end{tabular}

(Continued to the next page) 
Table 5. Continued

\begin{tabular}{lccc}
\hline Characteristic & $\begin{array}{c}\text { Asympto- } \\
\text { matic } \\
(\mathrm{n}=9)\end{array}$ & $\begin{array}{c}\text { Sympto- } \\
\text { matic } \\
(\mathrm{n}=10)\end{array}$ & $P$-value \\
\hline $\begin{array}{l}\text { Histopathological findings } \\
\text { Esophageal }\end{array}$ & $4(44.4)$ & $6(60.0)$ & \\
$\quad$ Normal & $4(44.4)$ & $3(30.0)$ & \\
$\quad$ Chronic active duodenitis & $1(11.1)$ & $1(10.0)$ & \\
Focal chronic active duodenitis & & & 0.78 \\
Gastric & $2(22.2)$ & $1(10.0)$ & \\
$\quad$ Normal & $4(44.4)$ & $6(60.0)$ & \\
$\quad$ Chronic active gastritis & $3(33.3)$ & $3(30.0)$ & \\
Focal enhanced gastritis & & & 0.62 \\
Duodenal & $8(88.9)$ & $8(80.0)$ & \\
$\quad$ Normal & $1(11.1)$ & $1(10.0)$ & \\
Aphthous ulcers & 0 & $1(10.0)$ & \\
$\quad$ Stricture & & & \\
\hline
\end{tabular}

Values are presented as number (\%).

${ }^{a}$ Fisher exact test.

tics, endoscopic, or histopathological findings (Table 5). The prevalence rate of UGICD according to the age of 18 years or younger versus older than 18 years was $24.6 \%$ and $23.8 \%$, respectively.

Upon stratifying UGICD involvement according to patient age ( $\leq 18$ years vs. $>18$ years), no significant difference was observed between the 2 groups $(P=1.0)$ with regards to the prevalence of UGICD. Also, there were no significant differences observed between the 2 groups with regards to the frequency of involvement of the esophagus, stomach, or duodenum (Table 2).

Bivariate analysis (Table 6) showed no significant association between UGICD and sex, age at diagnosis, extraintestinal manifestations, or complications. However, the association between UGICD and the disease localization demonstrated a statistical trend that did not reach statistical significant $(P=0.07)$ as ileal location was the most predominant in UGICD (57.8\%) compared to $28.8 \%$ found with non-UGICD patients. The disease behavior did not differ significantly between the UGICD and non-UGICD groups $(P=0.77)$.

Patients with UGICD had comparable rates of surgical resections $(2 / 19$ [10.5\%] vs. 5/59 [8.5\%], $P=1.0)$ and fistulizing disease $(3 / 19$ [15.8\%] vs. $5 / 59$ [8.5\%], $P=0.2)$ in contrast to patients without UGICD. No significant differences in the frequency of intestinal/colonic strictures $(P=1.0)$ or bowel perforations ( $P=1.0$ ) were observed. One (5.3\%) patient with UGICD developed an esophageal stricture and one (5.3\%) developed a gastric antral stricture that required treatment with corticosteroids intralesional injections and endoscopic balloon dilatation.

\section{DISCUSSION}

The ability to accurately estimate the prevalence of upper GI involvement of $\mathrm{CD}$ in adults is a challenging task, mainly because adult CD patients do not undergo routine diagnostic upper GI endoscopy unless they are symptomatic. A study in adults of prospective upper GI endoscopy in patients with CD found UGICD in $41 \%$ of the patients; only one-third of them were symptomatic. ${ }^{7}$ Another study found that $56 \%$ of adult patients with CD had UGICD when upper GI endoscopy was performed. ${ }^{8}$ Studies in adolescents and children who had simultaneous upper GI endoscopy at the time of diagnosis reported a prevalence of UGICD of $23 \%$ and $36 \%-53 \%$, respectively. ${ }^{4,16-18}$ Of the patients in our study cohort who had simultaneous upper GI endoscopy at baseline, the overall prevalence of UGICD was $17.5 \%$ for children and adolescents, and $31.3 \%$ for adults, consistent with previous reports. Our patients' age were skewed towards pediatric and adolescents, who constituted $73.1 \%$ of the cohort. The predominance of children and adolescents could be attributed to the recommendations made by the ESPGHAN revised Porto Criteria to perform upper GI endoscopy with ileocolonoscopy for all patients evaluated for possible IBD. ${ }^{6}$

CD gastritis is the most common form of UGICD that occurs in $50 \%$ at the initial presentation. It is often associated with CD duodenitis; therefore, it is referred to as "gastro-duodenal CD." ${ }^{\prime 1920}$ Gastro-duodenal CD was the most common form of UGICD in our cohort in both children/adolescents and adults (Table 2). It is associated with distal small bowel and colonic involvement in all patients, in agreement with previously reported literature. ${ }^{20-22}$ We observed no cases of isolated gastro-duodenal involvement, which has been reported in less than one-third of patients and often evolves into distal disease. ${ }^{20,21}$ Gastro-duodenal CD can be complicated by progression to fistula formation, stricture, or both..$^{20,22-24}$ One patient in this cohort developed a gastric antral stricture, and as a consequence gastric outlet obstruction that was managed by endoscopic balloon dilatation, trans-pyloric enteral feeding, and corticosteroids treatment; none had gastro-duodenal fistulae.

Esophageal involvement, which is the rarest form of UGICD 
Table 6. Bivariate Analysis Examining Associations with UGICD

\begin{tabular}{|c|c|c|c|c|}
\hline Variable & UGICD $(n=19)$ & Non UGICD $(n=59)$ & Total $(n=78)$ & $P$-value \\
\hline Sex & & & & 1.00 \\
\hline Male & $11(57.9)$ & $32(54.2)$ & $43(55.1)$ & \\
\hline Female & $8(42.1)$ & $27(45.8)$ & $35(44.9)$ & \\
\hline History of parental consanguinity & & & & 1.00 \\
\hline No & $15(78.9)$ & 45 (76.3) & $60(76.9)$ & \\
\hline Yes & $4(21.1)$ & $14(23.7)$ & $18(23.1)$ & \\
\hline Age at diagnosis (Montreal) & & & & 0.65 \\
\hline$<17 \mathrm{yr}$ & $9(47.4)$ & $35(59.3)$ & $44(56.4)$ & \\
\hline $17-40 \mathrm{yr}$ & $9(47.4)$ & $22(37.3)$ & $31(39.7)$ & \\
\hline$>40 \mathrm{yr}$ & $1(5.2)$ & $2(3.4)$ & $3(3.8)$ & \\
\hline Disease location (Montreal) & & & & 0.07 \\
\hline L1 (lleal) & $11(57.8)$ & $17(28.8)$ & $28(35.9)$ & \\
\hline L2 (Colonic) & $4(21.1)$ & $22(37.3)$ & $26(33.3)$ & \\
\hline L3 (Ileo-colonic) & $4(21.1)$ & $20(33.9)$ & $24(30.8)$ & \\
\hline Disease behavior (Montreal) & & & & 0.77 \\
\hline B1 (Non-stricturing \& non-penetrating) & $17(89.4)$ & $51(86.4)$ & $68(87.2)$ & \\
\hline B2 (Stricturing) & $1(5.3)$ & $6(10.2)$ & $7(9.0)$ & \\
\hline B3 (Penetrating) & $1(5.3)$ & $2(3.4)$ & $3(3.8)$ & \\
\hline \multicolumn{5}{|l|}{ Symptoms } \\
\hline Diarrhea & & & & 1.00 \\
\hline No & $5(26.3)$ & $17(28.8)$ & $22(28.2)$ & \\
\hline Yes & $14(73.7)$ & $42(71.2)$ & $56(71.8)$ & \\
\hline Fatigue & & & & 1.00 \\
\hline No & $10(52.6)$ & $29(49.2)$ & $39(50.0)$ & \\
\hline Yes & $9(47.4)$ & $30(50.8)$ & $39(50.0)$ & \\
\hline Dysphagia & & & & 0.06 \\
\hline No & $17(89.5)$ & $59(100)$ & $76(97.4)$ & \\
\hline Yes & $2(10.5)$ & 0 & $2(2.6)$ & \\
\hline Vomiting & & & & 0.08 \\
\hline No & $11(57.9)$ & $46(78)$ & $57(73.1)$ & \\
\hline Yes & $8(42.1)$ & $13(22)$ & $21(26.9)$ & \\
\hline Weight loss & & & & 0.59 \\
\hline No & $7(36.8)$ & $27(45.8)$ & 34 (43.6) & \\
\hline Yes & $12(63.2)$ & $32(54.2)$ & $44(56.4)$ & \\
\hline Aphthous stomatitis (mouth sores) & & & & 1.00 \\
\hline No & $17(89.5)$ & $53(89.8)$ & $70(89.7)$ & \\
\hline Yes & $2(10.5)$ & $6(10.2)$ & $8(10.3)$ & \\
\hline Eye inflammation (uveitis or scleritis) & & & & 1.00 \\
\hline No & $19(100)$ & $56(94.9)$ & 75 (96.2) & \\
\hline Yes & 0 & $3(5.1)$ & $3(3.8)$ & \\
\hline Perianal disease (fissures, fistulas, anal stenosis) & & & & 1.00 \\
\hline No & $17(89.5)$ & $53(89.8)$ & $70(89.7)$ & \\
\hline Yes & $2(10.5)$ & $6(10.2)$ & $8(10.3)$ & \\
\hline Joints pain & & & & 0.70 \\
\hline No & $17(89.5)$ & $51(86.4)$ & $68(87.2)$ & \\
\hline Yes & $2(10.5)$ & $8(13.6)$ & $10(12.8)$ & \\
\hline Presence of complications & & & & 1.00 \\
\hline No & $13(68.4)$ & $41(69.5)$ & $54(69.2)$ & \\
\hline Yes & $6(31.6)$ & $18(30.5)$ & $24(30.8)$ & \\
\hline
\end{tabular}

Values are presented as number (\%).

${ }^{a}$ Fisher exact test.

UGICD, upper GI CD. 
that has been reported to affect $3.3 \%$ to $6.8 \%$ of adults and $7.6 \%$ to $17.6 \%$ of children and adolescents, respectively, was found in $15.8 \%$ of our UGICD patients. ${ }^{5,25-28}$ The main challenges in the diagnosis of UGICD arise owing to the similarity between CD esophagitis and other common conditions such as reflux and eosinophilic esophagitis, which can cause symptoms that, resemble those for $\mathrm{CD}$ esophagitis. The presence of nonspecific histological findings also seldom makes the distinction very difficult. Twenty-one percent of patients with CD esophagitis also have gastro-duodenal or ileo-colonic disease. ${ }^{25}$ All our patients had associated distal small bowel and colon CD disease. As with gastro-duodenal CD, patients with CD esophagitis may develop a complicated pathology, including the progression to strictures and fistulae, which is very rare. However, the majority of patients with UGICD have inflammatory CD esophagitis. ${ }^{25,29}$ Only one patient in our cohort of 3 patients with esophageal involvement developed an esophageal stricture, and none had esophageal fistulae. This patient was managed with intensified medical treatment and esophageal balloon dilatation.

Patients with UGICD are at greater risk of a more complicated disease course and bowel damage towards either stricturing or penetrating disease, more recurrent symptoms with frequent flare ups, more hospitalizations, and a greater chance of requiring bowel resection. ${ }^{12,30}$ Our results did not show that patients with UGICD are more prone to penetrating disease or have a greater likelihood of requiring surgical resections, presumably because of a lack of statistical power owing to the small sample size we examined.

We acknowledge that our study is limited by size and design. The lacking data of smoking was one of the limitations. The use of regular Upper GI endoscopy without chromoendoscopy or image-enhanced endoscopy may be an additional limitation in this study, because these techniques may improve the detectability of lesion for UGICD. Future prospective studies are needed to delineate the progression of UGICD over time and to study various possible predictors of outcomes.

In conclusion, in this cohort of patients with CD who had undergone diagnostic upper GI endoscopy, $24.4 \%$ of patients had involvement of the upper GI tract, regardless of age.

\section{FINANCIAL SUPPORT}

The authors received no financial support for the research, authorship, and/or publication of this article.

\section{CONFLICT OF INTEREST}

No potential conflict of interest relevant to this article was reported.

\section{AUTHOR CONTRIBUTION}

Guarantor of the article: Saadah OI. Development of study concept and design: Mosli MH, Fallatah KB, Saadah OI, Elbaradie AA, Alshuaibi OH. Acquisition, analysis, and interpretation of the data: Fallatah KB, Howladar FT, Daiwali MT. Statistical analysis: Saadah OI, Mosli MH, Baumann C. Drafting of the manuscript: Mosli MH, Saadah OI. Critical revision of the manuscript for important intellectual content: Saadah OI, Mosli MH, Bokhary RY, Alsahafi MA, Baumann C, Qari YA, Peyrin-Biroulet L. Approval of final manuscript: all authors.

\section{ORCID}

Saadah OI https://orcid.org/0000-0002-3744-9907

Fallatah KB https://orcid.org/0000-0002-5314-6172

Baumann C https://orcid.org/0000-0003-4887-9459

Elbaradie AA https://orcid.org/0000-0002-7924-7166

Howladar FT https://orcid.org/0000-0002-8565-6169

Daiwali MT https://orcid.org/0000-0002-2799-7862

Alshuaibi OH https://orcid.org/0000-0002-1496-4308

Alsahafi MA https://orcid.org/0000-0002-9076-536X

Bokhary RY https://orcid.org/0000-0002-3372-1950

Qari YA https://orcid.org/0000-0002-8049-8106

Peyrin-Biroulet L https://orcid.org/0000-0003-2536-6618

Mosli MH https://orcid.org/0000-0002-6975-1297

\section{ACKNOWLEDGEMENTS}

We acknowledge Dr. Trevor Rawbone, Cardiff, UK, for English editing and proofreading of the manuscript.

\section{REFERENCES}

1. Kaser A, Zeissig S, Blumberg RS. Inflammatory bowel disease. Annu Rev Immunol 2010;28:573-621.

2. Maaser C, Sturm A, Vavricka SR, et al. ECCO-ESGAR Guideline for Diagnostic Assessment in IBD Part 1: initial diagnosis, monitoring of known IBD, detection of complications. J Crohns Colitis 2019;13:144-164.

3. Schwartzberg DM, Brandstetter S, Grucela AL. Crohn's dis- 
ease of the esophagus, duodenum, and stomach. Clin Colon Rectal Surg 2019;32:231-242.

4. Goodhand J, Dawson R, Hefferon M, et al. Inflammatory bowel disease in young people: the case for transitional clinics. Inflamm Bowel Dis 2010;16: 947-952.

5. Ramaswamy K, Jacobson K, Jevon G, Israel D. Esophageal Crohn disease in children: a clinical spectrum. J Pediatr Gastroenterol Nutr 2003;36:454-458.

6. Levine YY, Koletzko J, Turner D. ESPGHAN revised Porto criteria for the diagnosis of inflammatory bowel disease in children and adolescents. Zhonghua Er Ke Za Zhi 2016;54:728732 .

7. Horjus Talabur Horje CS, Meijer J, Rovers L, van Lochem EG, Groenen MJ, Wahab PJ. Prevalence of upper gastrointestinal lesions at primary diagnosis in adults with inflammatory bowel disease. Inflamm Bowel Dis 2016;22:1896-1901.

8. Alcántara M, Rodriguez R, Potenciano JL, Carrobles JL, Muñoz C, Gomez R. Endoscopic and bioptic findings in the upper gastrointestinal tract in patients with Crohn's disease. Endoscopy 1993;25:282-286.

9. Wagtmans MJ, van Hogezand RA, Griffioen G, Verspaget HW, Lamers CB. Crohn's disease of the upper gastrointestinal tract. Neth J Med 1997;50:S2-S7.

10. Witte AM, Veenendaal RA, Van Hogezand RA, Verspaget HW, Lamers CB. Crohn's disease of the upper gastrointestinal tract: the value of endoscopic examination. Scand J Gastroenterol Suppl 1998;225:100-105.

11. Korelitz BI, Waye JD, Kreuning J, et al. Crohn's disease in endoscopic biopsies of the gastric antrum and duodenum. Am J Gastroenterol 1981;76:103-109.

12. Song XM, Gao X, Li MZ, et al. Clinical features and risk factors for primary surgery in 205 patients with Crohn's disease: analysis of a South China cohort. Dis Colon Rectum 2011;54:11471154.

13. Magro F, Langner C, Driessen A, et al. European consensus on the histopathology of inflammatory bowel disease. J Crohns Colitis 2013;7:827-851.

14. Feakins RM; British Society of Gastroenterology. Inflammatory bowel disease biopsies: updated British Society of Gastroenterology reporting guidelines. J Clin Pathol 2013;66:10051026.

15. Geboes K, Janssens J, Rutgeerts P, Vantrappen G. Crohn's disease of the esophagus. J Clin Gastroenterol 1986;8:31-37.

16. Ammoury RF, Pfefferkorn MD. Significance of esophageal Crohn disease in children. J Pediatr Gastroenterol Nutr 2011;
52:291-294.

17. Crocco S, Martelossi S, Giurici N, Villanacci V, Ventura A. Upper gastrointestinal involvement in paediatric onset Crohn's disease: prevalence and clinical implications. J Crohns Colitis 2012;6:51-55.

18. Renault M, Goodier A, Subramony C, Hood B, Bishop P, Nowicki M. Age-related differences in granulomatous gastritis: a retrospective, clinicopathological analysis. J Clin Pathol 2010; 63:347-350.

19. Goldstein NS, Lewin KJ, Doty JE. Gastrointestinal tract. Pathology (Phila) 1996;3:349-365.

20. Kefalas CH. Gastroduodenal Crohn's disease. Proc (Bayl Univ Med Cent) 2003;16:147-151.

21. Reynolds HL Jr, Stellato TA. Crohn's disease of the foregut. Surg Clin North Am 2001;81:117-135.

22. Yamamoto T, Bain IM, Connolly AB, Keighley MR. Gastroduodenal fistulas in Crohn's disease: clinical features and management. Dis Colon Rectum 1998;41:1287-1292.

23. Isaacs KL. Upper gastrointestinal tract endoscopy in inflammatory bowel disease. Gastrointest Endosc Clin N Am 2002; 12:451-462.

24. Pichney LS, Fantry GT, Graham SM. Gastrocolic and duodenocolic fistulas in Crohn's disease. J Clin Gastroenterol 1992; 15:205-211.

25. De Felice KM, Katzka DA, Raffals LE. Crohn's disease of the esophagus: clinical features and treatment outcomes in the biologic era. Inflamm Bowel Dis 2015;21:2106-2113.

26. Decker GA, Loftus EV Jr, Pasha TM, Tremaine WJ, Sandborn WJ. Crohn's disease of the esophagus: clinical features and outcomes. Inflamm Bowel Dis 2001;7:113-119.

27. Mashako MN, Cezard JP, Navarro J, et al. Crohn's disease lesions in the upper gastrointestinal tract: correlation between clinical, radiological, endoscopic, and histological features in adolescents and children. J Pediatr Gastroenterol Nutr 1989;8: 442-446.

28. Ruuska T, Vaajalahti P, Arajärvi P, Mäki M. Prospective evaluation of upper gastrointestinal mucosal lesions in children with ulcerative colitis and Crohn's disease. J Pediatr Gastroenterol Nutr 1994;19:181-186.

29. Yamamoto T, Fazio VW, Tekkis PP. Safety and efficacy of strictureplasty for Crohn's disease: a systematic review and metaanalysis. Dis Colon Rectum 2007;50:1968-1986.

30. Murray JJ, Schoetz DJ Jr, Nugent FW, Coller JA, Veidenheimer MC. Surgical management of Crohn's disease involving the duodenum. Am J Surg 1984;147:58-65. 